\title{
Risk of Embolization During Carotid Revascularization Procedures and The Role of Neuroimaging
}

\author{
Mohammed A Almekhlafi, MD, MSc, FRCPC ${ }^{*}$ (D); Abdulrahman Ali Alghamdi ${ }^{\dagger}$; Fouzi Bala, $\mathrm{PhD}^{\ddagger}$ (D) \\ Departments of Clinical Neurosciences, Radiology, and Community Health Sciences, University of Calgary ${ }^{\star}$, Calgary AB, Canada; Department of \\ Medicine, King Abdulaziz University ${ }^{\dagger}$, Jeddah, Saudi Arabia; Department of Neuroradiology, University of Lille ${ }^{\ddagger}$, Lille, France
}

Atherosclerotic carotid stenosis is an important cause of stroke. The advent of non-invasive carotid imaging using Doppler ultrasound and computerized tomography angiography has increased the number of patients who are diagnosed with and referred for revascularization of carotid stenosis. Both surgical or endovascular treatments for carotid stenosis carry a risk of brain embolization of plaque debris or in-situ thrombi. These emboli can be detected during these procedures using transcranial Doppler or post-procedures on diffusion magnetic resonance imaging. We review the literature on the incidence and detection of brain embolization during carotid revascularization procedures. We also describe some of the promising technologies to reduce embolization associated with carotid stenting.

\section{J Neurosonol Neuroimag 2020;12(1):1-9}

Key Words: Carotid stenosis; Carotid artery thrombosis; Endarterectomy, carotid; Stenting; Stroke
Received: January 29, 2020

Revised: February 24, 2020

Accepted: March 6, 2020

Correspondence:

Mohammed A Almekhlafi, $\mathrm{MD}, \mathrm{MSc}, \mathrm{FRCPC}$

Departments of Clinical

Neurosciences, Radiology, and Community Health Sciences, Hotchkiss Brain Institute and O’Brien Institute for Public Health, Cumming School of Medicine, University of Calgary Foothills Medical Centre, 1403 - 29th St. NW, Calgary, AB T2N 2T9, Canada

Tel: +1-403944 1883

Fax: +1-403 9442611

E-mail: mohammed.almekhlafi1@ucalgary.ca

\section{INTRODUCTION}

Up to a fifth of cases of acute ischemic stroke and transient ischemic attack (TIA) result from atherosclerotic carotid artery stenosis. ${ }^{1,2}$ Carotid stenosis leads to stroke by a number of mechanisms. ${ }^{3}$ Thrombi may form on top of carotid plaques and acutely occlude the carotid artery. Alternatively, a thrombus formed on the carotid plaque embolizes to one or more of the intracranial arteries. Lastly, a severely narrowed carotid artery can lead to brain hypoperfusion and infarction of certain brain areas which have tenuous blood flow; ${ }^{4}$ the so-called border zones stroke.

C Miller Fischer was among the first to point out the relationship between carotid stenosis and the development of ischemic stroke and TIA., ${ }^{5,6}$ At that time, catheter angiography was the only possible way to assess the carotid artery which, at that time, involved surgical cut- down of the carotid artery to inject the contrast into the artery. ${ }^{7}$ With the development of non-invasive imaging techniques, the role of internal carotid artery (ICA) stenosis in stroke became increasingly recognized. Nowadays, carotid artery can be imaged using computerized tomography (CT) angiography, magnetic resonance (MR) angiography, ultrasound (US) Doppler, and catheter angiography through puncturing the femoral or radial arteries. The degree of stenosis is measured by convention using the North American Symptomatic Carotid Endarterectomy Trial (NASCET) method. The degree of stenosis is calculated from the ratio of the diameter of ICA distal to the site of stenosis to the diameter of the area with maximum stenosis. ${ }^{8,9}$ The stenosis is considered severe when it is equal or more than $70 \%$, moderate when $50 \%$ to $69 \%$ and mild when less than $50 \%$ although the terminology used is considerably variable. 
Several factors have been linked to the development of carotid stenosis. Among those, age is the strongest and most consistent risk factor in incident carotid stenosis. ${ }^{10-13}$ Population-based studies report a prevalence of $0.5 \%$ for carotid stenosis, defined as narrowing equal or greater than $50 \%$, by the sixth decade of life, but increases to $10 \%$ by age 80 years. ${ }^{10}$ Prevalence of carotid stenosis is twice in males compared to females. ${ }^{11}$ This difference is still noted after adjusting for other factors and cannot be explained on the basis of hormonal factors since hormone replacement therapy in the Heart and Estrogen/Progestin Replacement Study (HERS) study did not delay progression of carotid disease. ${ }^{14}$ Smoking is also a major risk factor even after the adjustment for other factors as age, blood pressure, and body mass index. ${ }^{15,16}$

\section{CAROTID REVASCULARIZATION PROCEDURES}

\section{Carotid endarterectomy}

The standard treatment for symptomatic carotid stenosis is carotid endarterectomy (CEA) ${ }^{17}$ CEA was first successfully performed in the $1950^{\prime}$ 's. ${ }^{18}$ Since then, the number of procedures performed exponentially increased with the growing experience and improved safety. ${ }^{5,19}$ CEA acquired credibility and momentum as a stroke preventative therapy following the publication of the NASCET ${ }^{9}$ and the European Carotid Surgery Trial in $1991 .^{20}$ Prior to that, surgeons performed endarterectomy based on reports of low rates of perioperative complications $^{21,22}$ despite the negative results of prior randomized controlled trials (RCT) ${ }^{23,24}$ and others describing a non-significant trend in favor of surgery. ${ }^{25}$

The analysis of the pooled data of 6,092 patients with 35,000 patients-years of follow-up from the North American and European studies showed a highly favourable outcome with surgery compared to medical therapy. ${ }^{26}$ This effect was strongest in patients with $70 \%$ or more stenosis (excluding near-occlusion) with an absolute risk reduction (ARR) of $16 \%$ ( $p<0.001$ ) for the 5-year risk of ipsilateral ischemic stroke. There was minor benefit from surgery in those with $50-69 \%$ stenosis (ARR 4.6\%, $p=0.04$ ), and no benefit for those with less than $50 \%$ stenosis (ARR 3.2\%, $p=0.6$ ).

\section{Carotid angioplasty and stenting}

A less invasive treatment for symptomatic carotid stenosis is carotid angioplasty and stenting. An approach that was initially reserved for subjects with a high surgical risk, stenting has been increasingly recognized as a potential alternative to endarterectomy.

1) Overview of the steps of carotid angioplasty and stenting

Stenting procedures are typically performed under intravenous conscious sedation supported by an anesthesiologist. A common femoral artery access is used to advance the various catheters, and devices through the aortic arch to the common and then internal carotid artery. Once in the common carotid artery, the site of narrowing is crossed with a distal protection device intended to capture any embolic debris that might dislodge from the atherosclerotic plaque during the procedure. Pre-stenting angioplasty dilatation of the narrow carotid artery is then performed using a balloon. Following that, the stent is deployed and post-stenting dilatation using a balloon is sometimes needed to achieve the maximum possible dilatation at the site of narrowing. The protection device is then removed and the puncture site in the femoral artery is sealed using a closure device.

\section{Studies comparing endarterectomy to stenting}

Initial studies comparing endarterectomy vs. stenting were not in favor of stenting. However, the largest study comparing endarterectomy to stenting: carotid revascularization endarterectomy vs. stenting trial (CREST), did not show a difference in the composite outcomes between the two modality. ${ }^{27}$ CREST enrolled a total of 2,502 patients (47\% asymptomatic) and showed no significant difference between stenting and endarterectomy in a composite outcome of 30-day risk of stroke, death, and myocardial infarctions (MI). However, there were more stroke cases within 30 days of stenting (4.1\% vs. $2.3 \%$; $p=0.01$ ) but fewer MI cases (1.1\% vs. $2.3 \%$; $\mathrm{p}=0.03$ ). This supports prior randomized trials among symptomatic patients which reported more favorable early safety with $\mathrm{CEA}^{28,29}$ but similar long-term efficacy. A recent meta-analysis of 20 RCTs showed that the 
30-day stroke/death rate was significantly higher after CAS compared with CEA in asymptomatic patients (odds ratio [OR], 1.64; 95\% confidence interval [CI], 1.02 to 2.64) and symptomatic patients (OR, 1.71; 95\% CI, 1.38 to 2.11). After 30 days, the ipsilateral stroke rate is identical for both. ${ }^{3 \circ}$ Current guidelines recommend CAS as an alternative to CEA in patients at average or low risk of complications with endovascular interventions. ${ }^{17}$ It is also reasonable to consider CAS in patients with a high surgical risk due to anatomic (e.g. high carotid bifurcation level, contralateral carotid occlusion) or medical conditions or in specific conditions as radiation-induced stenosis or restenosis after CEA. Patients who are intolerant to dual antiplatelet therapy, those with poor kidney function, tortuous vascular access, and those allergic to contrast agents are better treated with CEA.

\section{BRAIN EMBOLIZATION ASSOCIATED WITH CAROTID REVASCULARIZATION}

A number of prospective studies described high incidence of new ischemic brain lesions on diffusion-weighted imaging (DWI) following carotid revascularization (Fig. 1A). ${ }^{31}$ However, none of these studies was randomized which limits the validity of these results.

The only trial that compared the incidence of new DWI lesions in patients randomized to stenting vs. endarterectomy is the MR sub-study of the International Carotid Stenting Study (ICSS). The ICSS was a randomized trial comparing stenting vs. endarterectomy in 1,713 patients with carotid stenosis. The primary endpoint was fatal or disabling stroke in any territory after randomization to the end of follow-up with a median of 4.2 years (interquartile range [IQR], 3.0-5.2; maximum 10.0)
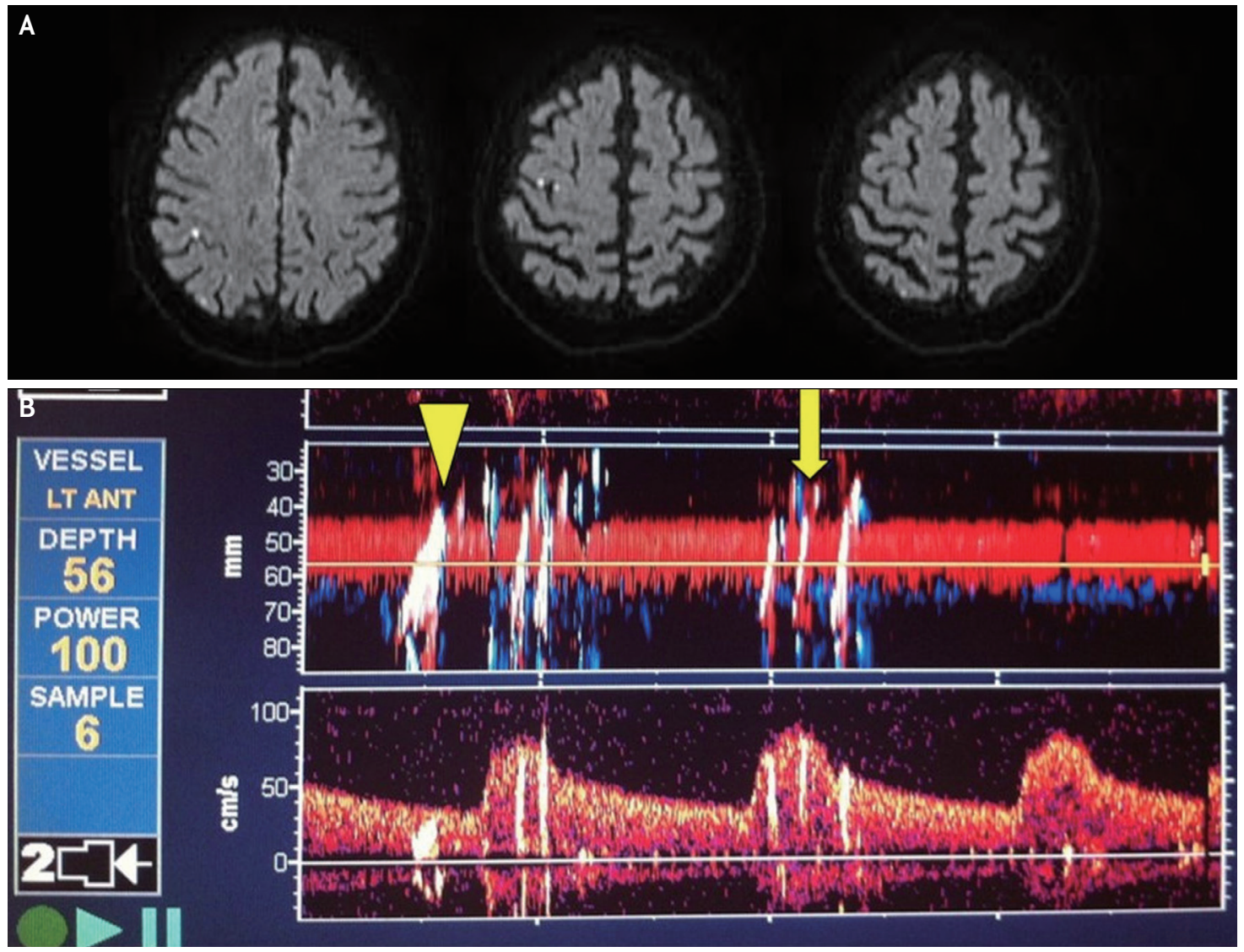

FIG. 1. (A) Diffusion-weighted MRI of the brain in a patient who underwent right carotid stenting showing embolic shower of the right hemisphere. The patient remained asymptomatic. (B) An example of embolic signals recorded during carotid stenting on trans cranial Doppler with Relative Energy Index of MES (REIM) $>1.0$ (arrow head) and REIM $<1$ (arrow). 
and it was similar between the two groups (6.4\% vs. 6.5\%; hazard ratio [HR], 1.06; 95\% CI, 0.72-1.57, $p=0.77) .{ }^{32}$ The ICSS MR sub-study included 231 patients from seven centers. Patients underwent brain magnetic resonance imaging (MRI) 1-7 days before treatment, 1-3 days after treatment (post-treatment scan), and 27-33 days after treatment. The primary endpoint was one or more DWI lesions on post-treatment scan. This occurred in $50 \%$ of 124 patients in the stenting arm compared to $17 \%$ of 107 patients in the endarterectomy arm. These lesions produced no clinical symptoms in $85 \%$ of affected patients in the stenting arm, and in $83 \%$ of those in the endarterectomy arm. ${ }^{33}$ This proves the high risk of brain embolization during these procedures and that most of these emboli produce no immediate clinical symptoms.

The highest risk of stroke following stenting is during or immediately after the procedure, as was showed in CREST. The median time from the date of procedure to stroke was o day (IQR, 4 days). Stroke on the procedure date occurred twice as frequently in the CAS arm compared to CEA (60\% vs. $43 \%) .{ }^{34}$

An updated meta-analysis of 59 studies $(5,431 \mathrm{pa}-$ tients) reported that more patients had DWI brain hits after stenting compared to endarterectomy (37.4\% vs. 13.0\%). ${ }^{32}$ Clinical strokes and TIAs were also higher after stenting (4.1\% vs. $1.8 \%$ ). Protective devices use and type (proximal vs. distal) did not influence the symptomatic vs. silent events associated with stenting.

\section{Impact of "silent" embolization to the brain}

Despite the silent clinical nature of DWI lesions with carotid revascularization, experimental evidence has documented brain tissue damage corresponding to DWI lesions. In a rodent model of ischemia, significant ultra-structural damage was observed in these areas. ${ }^{35}$ Human studies have also cautioned from labelling these abnormalities as silent. "Silent" brain infarcts at baseline, defined as focal hyperintensity on T2 MR sequence at least $3 \mathrm{~mm}$ in diameter, doubled the risk of future dementia in a prospective, population-based study.$^{36}$ Although cognitive impairment has been described in patients with carotid stenosis, this risk is not lowered by carotid revascularization in all patients. ${ }^{37,38}$ One potential explanation is brain embolization during these interventions which correlates with significant cognitive decline. Indeed, in a prospective study of 100 consecutive patients undergoing endarterectomy, persistent embolization on intra-operative trans cranial Doppler (TCD) after restoration of flow correlated with development of cognitive deficits. ${ }^{39}$ However, there was a non-significant trend relating the overall number of emboli during the surgery in those who developed cognitive deficits (median emboli count 52; 95\% CI, 35.5 to 100) when compared to those with no new cognitive change (median, 32.5; 95\% CI, 24 to 44).

\section{TRANSCRANIAL DOPPLER USE IN CAROTID REVASCULARIZATION PROCEDURES}

\section{Introduction}

Emboli generate a short-lived high-intensity signal that can be detected on TCD. These micro embolic signals (MES) has high sensitivity and specificity for true embolic material (thrombus, platelet aggregates, and atheroma) in animal and laboratory models. ${ }^{40}$ Criteria were established in 1995 to differentiate MES from artifacts that may result from movements of the TCD probe. ${ }^{41}$ These features include uni-directionality, short duration (less than $300 \mathrm{~ms}$ ), amplitude of more than $3 \mathrm{~dB}$ above the Doppler background, and typical "chirping" sound. However, differentiating particulate MES from gaseous bubbles is not always clear. In addition, special TCD modes are required to quantify the size of these MES. MES are most frequently seen in large artery disease including symptomatic carotid stenosis where they correlate with the number of DWI lesions on MRI. ${ }^{42}$

1) Estimating the size of MES using TCD

Attempts to estimate the size of MES based on their characteristics on single-gate spectrogram TCD were restricted by the limited information on MES characteristics provided by the single-gate TCD. ${ }^{43}$ This has been overcome by the power M-mode Doppler currently available with digital TCD. It enables the simultaneous estimation of multi-gate travel time, maximal duration, travel length, and MES velocity; all not measured by the spectrogram TCD. ${ }^{44}$ 
Assuming that emboli are spherical, an equation for approximating the size of emboli according to their relative energy, the so-called Relative Energy Index of MES (REIM), has been reported. ${ }^{45}$ Investigators have shown that malignant emboli, defined as REIM >1, were found to be associated with larger baseline DWI and to be predictive of poor clinical outcome ( $m R S \geq 2$ ) (Fig. $1 \mathrm{~B})$.

2) Use of TCD to detect embolization in carotid stenting A number of studies have shown that MES during stenting are associated with subsequent stroke. In a study comparing incidence of MES during stenting with vs. without protective device use in 509 patients, more MES were noted in patients treated with these devices. ${ }^{46}$ Although protective device handling has accounted for less than $7 \%$ of the total MES load in those patients, there were higher counts in the wiring and stent deployment phases in patients who had protective devices. The infrequent development of neurological sequelae did not allow any correlation of the MES count with neurologic outcome. If diffusion MR imaging were used as a surrogate outcome in those patients, better correlation could have been achieved. In addition, about a third of the study population were asymptomatic. It is unknown whether the carotid plaque characteristics in those patients are different from the symptomatic patients making extrapolating these results to all-symptomatic cohorts inaccurate.

The association between emboli on TCD and DWI lesions during CAS was prospectively investigated in 30 patients (23\% asymptomatic). The study showed a high incidence of embolic signal during the procedure, particularly during stent deployment. Most subjects (80\%) developed new DWI lesions but only $6.7 \%$ developed subsequent clinical deficits. There were no association between the total count of MES and DWI lesions' number but malignant emboli (REIM >1) correlated with new DWI hits. ${ }^{47}$

\section{3) Use of TCD in CEA}

Padayachee et $\mathrm{al} .^{48}$ noted that 17 of 19 patients monitored with TCD during CEA had signals of abnormally high amplitudes. These are ascribed to turbulent blood flow or microscopic air bubbles and had no correlation with adverse effects in the patients.

Wolf et al. ${ }^{49}$ demonstranted on 33 patients monitered during CEA by using TCD that microembolic signals (MES) occur more frequently during shunting and declamping, but the most vulnerable stages of the procedure were dissection and shunting because of the correlation found with the occurrence of MES.

\section{CURRENT AND PROMISING PROTECTIVE TECHNIQUES DURING CAROTID STENTING}

This high rate of brain embolization during carotid stenting shows that available protective therapies are not enough. Brain protection during stenting is centered on the use of a net-like distal protection device that aims to capture any emboli during the procedure..$^{50}$ Two single-center randomized trials showed no difference in DWI incidence following stenting with vs. without the use of distal protection devices. ${ }^{48,49}$ In centers using distal protection devices for stenting in the ICSS, new DWI lesions occurred in $73 \%$ of stenting patients vs. $34 \%$ in centers not using these devices. ${ }^{33}$ On the other hand, a metanalysis of 25 studies reported a significant decrease in the risk of stroke associated with CAS when distal protection device is used (OR, 0.63; 95\% CI, $0.48-0.84 ; p=0.001$ ).

A number of procedural modifications are promising to reduce the risk of embolization (discussed below). In addition, the role of plaque features in selecting patients for CEA or CAS might become relevant with the advent of non-invasive plaque imaging. Such features could include plaque neovascularization (contrast-enhanced US) and volume (3D US), plaque, and plaque inflammation (positron emission tomography-computed tomography). ${ }^{51,52}$

\section{Stent design}

The use of alternative stent design is a promising solution to reduce embolization during stenting. The use of closed-cell stent design was associated with lower risk of stroke compared to open-cell design in a pooled analysis of three randomized trials that compared stenting to endarterectomy (10.3\% vs. $6.0 \%$; $p$-value 0.002).53 An emerging stent design that uses an inner tightly packed mesh that lines an outer flexible (openor close-cell) stent with the aim to prevent plaque pro- 
lapse through the stent during the procedure. There are currently two such "micromesh" stents design Casper (MicroVention Inc, Tustin, California, USA; which is also marketed as Roadsaver stent by Terumo, Tokyo, Japan) and the CGuard stent (InspireMD, Boston, MA, USA). The evidence supporting the safety of these stents is accumulating although there was no clear difference in safety (clinical and radiological strokes) of the CGuard stents compared to close-cell stents in a small randomized trial. ${ }^{54}$

\section{Primary stenting}

All stents used for CAS are self-expanding. Nonetheless, balloon angioplasty post stent deployment has become a routine step of CAS in many centers to improve the stent apposition to the vessel wall. This step carries a potential risk of forcing plaque particles through the stent struts and thus increasing the risk of distal embolization. We have shown that malignant MES during CAS were significantly high during post stenting angioplasty. ${ }^{47}$ Similar observation was reported by others in which the rate of peri-CAS stroke was lowered by nearly half after eliminating post stent angioplasty, without increasing the risk of restenosis. ${ }^{55,56}$ These observations called for adopting primary stenting, i.e. without post angioplasty. However, angioplasty may still be required for calcified plaques in which restenosis rates were high if post stent angioplasty was not sued.

\section{Transcervical approach}

Another promising advent is the use of the transcervical approach to carotid stenting. This is performed using a short incision at the base of the neck to reach the common carotid artery and create flow-reversal through a carotid to jugular (or femoral) vein fistula. The reversal of the flow aims to redirect any emboli that could occur during subsequent crossing and stenting of the carotid artery. ${ }^{57}$ This technique has demonstrated encouraging outcomes compared to the standard transfemoral approach. In a meta-analysis comparing the two approaches, stenting using transfemoral route was associated with a higher risk of 30-day clinical stroke (OR, 1.98; 95\% CI, 1.08 to 3.63; $p=0.027$ ) and new DWI lesions (OR, 2.97; 95\% CI, 1.48 to 5.96; $p=0.002$ ) compared to the transcervical approach. ${ }^{5}$ No difference in complications were noted between the two approaches.

\section{CONCLUSIONS}

Carotid stenting is increasingly used despite the small but significant increased risks of stroke compared to endarterectomy. The use of imaging with MRI and TCD have improved our understanding of the procedure safety and of the steps associated with higher risk of brain embolization during stenting. These imaging modalities will continue to play a key role in assessing the impact of promising modifications on the approach and devices used during stenting.

\section{REFERENCES}

1. Foulkes MA, Wolf PA, Price TR, Mohr JP, Hier DB. The Stroke Data Bank: design, methods, and baseline characteristics. Stroke. 1988;19:547-554.

2. Inzitari D, Eliasziw M, Gates P, Sharpe BL, Chan RK, Meldrum HE, et al. The causes and risk of stroke in patients with asymptomatic internal-carotid-artery stenosis. North American Symptomatic Carotid Endarterectomy Trial Collaborators. N Engl J Med. 2000;342:1693-1700.

3. Rothwell PM. Carotid endarterectomy, stenting, and other prophylactic interventions. Handb Clin Neurol. 2009;94:12951325 .

4. Bozzao A, Floris R, Gaudiello F, Finocchi V, Fantozzi LM, Simonetti G. Hemodynamic modifications in patients with symptomatic unilateral stenosis of the internal carotid artery: evaluation with MR imaging perfusion sequences. AJNR Am J Neuroradiol. 2002;23:1342-1345.

5. Estol CJ. Dr C. Miller Fisher and the history of carotid artery disease. Stroke. 1996;27:559-566.

6. Fisher M. Occlusion of the carotid arteries: further experiences. AMA Arch Neurol Psychiatry. 1954;72:187-204.

7. Caplan LR. Caplan's stroke: a clinical approach. $4^{\text {th }}$ ed. Philadelphia: Elsevier Inc. 2009.

8. American College of Cardiology Foundation, American Society of Interventional \& Therapeutic Neuroradiology, Society for Cardiovascular Angiography and Interventions, Society for Vascular Medicine and Biology, Society of Interventional Radiology, Bates ER, et al. ACCF/SCAI/SVMB/ 
SIR/ASITN 2007 clinical expert consensus document on carotid stenting: a report of the American College of Cardiology Foundation task force on clinical expert consensus documents (ACCF/SCAI/SVMB/SIR/ASITN clinical expert consensus document committee on carotid stenting). J Am Coll Cardiol. 2007;49:126-170.

9. North American Symptomatic Carotid Endarterectomy Trial Collaborators, Barnett HJM, Taylor DW, Haynes RB, Sackett DL, Peerless SJ, et al. Beneficial effect of carotid endarterectomy in symptomatic patients with high-grade carotid stenosis. N Engl J Med. 1991;325:445-453.

10. O'Leary DH, Polak JF, Kronmal RA, Kittner SJ, Bond MG, Wolfson SK Jr, et al. Distribution and correlates of sonographically detected carotid artery disease in the Cardiovascular Health Study. The CHS Collaborative Research Group. Stroke. 1992;23:1752-1760.

11. Prati P, Vanuzzo D, Casaroli M, Di Chiara A, De Biasi F, Feruglio GA, et al. Prevalence and determinants of carotid atherosclerosis in a general population. Stroke. 1992;23:17051711.

12. Fabris F, Zanocchi M, Bo M, Fonte G, Poli L, Bergoglio I, et al. Carotid plaque, aging, and risk factors. A study of 457 subjects. Stroke. 1994;25:1133-1140.

13. Joakimsen O, Bonaa KH, Stensland-Bugge E, Jacobsen BK. Age and sex differences in the distribution and ultrasound morphology of carotid atherosclerosis: the Troms $\varnothing$ study. Arterioscler Thromb Vasc Biol. 1999;19:3007-3013.

14. Byington RP, Furberg CD, Herrington DM, Herd JA, Hunninghake D, Lowery $\mathrm{M}$, et al. Effect of estrogen plus progestin on progression of carotid atherosclerosis in postmenopausal women with heart disease: HERS B-mode substudy. Arterioscler Thromb Vasc Biol. 2002;22:1692-1697.

15. Haapanen A, Koskenvuo M, Kaprio J, Kesäniemi YA, Heikkilä K. Carotid arteriosclerosis in identical twins discordant for cigarette smoking. Circulation. 1989;80:10-16.

16. Wilson PW, Hoeg JM, D'Agostino RB, Silbershatz H, Belanger AM, Poehlmann $\mathrm{H}$, et al. Cumulative effects of high cholesterol levels, high blood pressure, and cigarette smoking on carotid stenosis. N Engl J Med. 1997;337:516-522.

17. Kernan WN, Ovbiagele B, Black HR, Bravata DM, Chimowitz MI, Ezekowitz MD, et al. Guidelines for the prevention of stroke in patients with stroke and transient ischemic attack: a guideline for healthcare professionals from the American Heart Association/American Stroke Association. Stroke. 2014;45:2160-2236.

18. De Bakey ME, Crawford ES, Cooley DA, Morris GC Jr.
Surgical considerations of occlusive disease of innominate, carotid, subclavian, and vertebral arteries. Ann Surg. 1959;149:690-710.

19. Thompson JE, Talkington CM. Carotid endarterectomy. Adv Surg. 1993;26:99-131.

20. MRC European Carotid Surgery Trial: interim results for symptomatic patients with severe (70-99\%) or with mild (o29\%) carotid stenosis. European Carotid Surgery Trialists' Collaborative Group. Lancet. 1991;337:1235-1243.

21. Baker WH, Littooy FN, Greisler HP, Dorner DB, Ford JJ Jr, Mungas JE, et al. Carotid endarterectomy in private practice by fellowship-trained surgeons. Stroke. 1987;18:957-958.

22. Sundt TM Jr, Whisnant JP, Houser OW, Fode NC. Prospective study of the effectiveness and durability of carotid endarterectomy. Mayo Clin Proc. 1990;65:625-635.

23. Fields WS, Maslenikov V, Meyer JS, Hass WK, Remington RD, Macdonald M. Joint study of extracranial arterial occlusion. V. Progress report of prognosis following surgery or nonsurgical treatment for transient cerebral ischemic attacks and cervical carotid artery lesions. JAMA. 1970;211:1993-2003.

24. Shaw DA, Venables GS, Cartlidge NE, Bates D, Dickinson $\mathrm{PH}$. Carotid endarterectomy in patients with transient cerebral ischaemia. J Neurol Sci. 1984;64:45-53.

25. Mayberg MR, Wilson SE, Yatsu F, Weiss DG, Messina L, Hershey LA, et al. Carotid endarterectomy and prevention of cerebral ischemia in symptomatic carotid stenosis. Veterans Affairs Cooperative Studies Program 309 Trialist Group. JAMA. 1991;266:3289-3294.

26. Rothwell PM, Eliasziw M, Gutnikov SA, Fox AJ, Taylor DW, Mayberg MR, et al. Analysis of pooled data from the randomised controlled trials of endarterectomy for symptomatic carotid stenosis. Lancet. 2003;361:107-116.

27. Brott TG, Hobson RW 2nd, Howard G, Roubin GS, Clark WM, Brooks W, et al. Stenting versus endarterectomy for treatment of carotid-artery stenosis. N Engl J Med. 2010;363:11-23.

28. SPACE Collaborative Group, Ringleb PA, Allenberg J, Brückmann H, Eckstein HH, Fraedrich G, et al. 30 day results from the SPACE trial of stent-protected angioplasty versus carotid endarterectomy in symptomatic patients: a randomised non-inferiority trial. Lancet. 2006;368:1239-1247.

29. Brotto LA, Yule M, Breckon E. Psychological interventions for the sexual sequelae of cancer: a review of the literature. J Cancer Surviv. 2010;4:346-360.

30. Batchelder AJ, Saratzis A, Ross Naylor A. Editor's choice 
- overview of primary and secondary analyses from 20 randomised controlled trials comparing carotid artery stenting with carotid endarterectomy. Eur J Vasc Endovasc Surg. 2019;58:479-493.

31. Schnaudigel S, Gröschel K, Pilgram SM, Kastrup A. New brain lesions after carotid stenting versus carotid endarterectomy: a systematic review of the literature. Stroke. 2008;39:1911-1919.

32. Cho SM, Deshpande A, Pasupuleti V, Hernandez AV, Uchino K. Radiographic and symptomatic brain ischemia in CEA and CAS: a systematic review and meta-analysis. Neurology. 2017;89:1977-1984.

33. Bonati LH, Jongen LM, Haller S, Flach HZ, Dobson J, Nederkoorn PJ, et al. New ischaemic brain lesions on MRI after stenting or endarterectomy for symptomatic carotid stenosis: a substudy of the International Carotid Stenting Study (ICSS). Lancet Neurol. 2010;9:353-362.

34. Hill MD, Brooks W, Mackey A, Clark WM, Meschia JF, Morrish WF, et al. Stroke after carotid stenting and endarterectomy in the carotid revascularization endarterectomy versus stenting trial (CREST). Circulation. 2012;126:3054-3061.

35. Ringer TM, Neumann-Haefelin T, Sobel RA, Moseley ME, Yenari MA. Reversal of early diffusion-weighted magnetic resonance imaging abnormalities does not necessarily reflect tissue salvage in experimental cerebral ischemia. Stroke. 2001;32:2362-2369.

36. Vermeer SE, Prins ND, den Heijer T, Hofman A, Koudstaal PJ, Breteler MM. Silent brain infarcts and the risk of dementia and cognitive decline. N Engl J Med. 2003;348:12151222.

37. Auperin A, Berr C, Bonithon-Kopp C, Touboul PJ, Ruelland I, Ducimetiere P, et al. Ultrasonographic assessment of carotid wall characteristics and cognitive functions in a community sample of 59- to 71-year-olds. The EVA Study Group. Stroke. 1996;27:1290-1295.

38. De Rango P, Caso V, Leys D, Paciaroni M, Lenti M, Cao P. The role of carotid artery stenting and carotid endarterectomy in cognitive performance: a systematic review. Stroke. 2008;39:3116-3127.

39. Gaunt ME, Martin PJ, Smith JL, Rimmer T, Cherryman G, Ratliff DA, et al. Clinical relevance of intraoperative embolization detected by transcranial Doppler ultrasonography during carotid endarterectomy: a prospective study of 100 patients. Br J Surg. 1994;81:1435-1439.

40. Russell D, Madden KP, Clark WM, Sandset PM, Zivin JA. Detection of arterial emboli using Doppler ultrasound in rabbits. Stroke. 1991;22:253-258.

41. Basic identification criteria of Doppler microembolic signals. Consensus Committee of the Ninth International Cerebral Hemodynamic Symposium. Stroke. 1995;26:1123.

42. King A, Markus HS. Doppler embolic signals in cerebrovascular disease and prediction of stroke risk: a systematic review and meta-analysis. Stroke. 2009;40:3711-3717.

43. Gaunt ME, Smith JL, Martin PJ, Evans DH, Bell PR, Naylor AR. Detection of symptomless cerebral emboli. Lancet. 1994;343:1577-1578.

44. Moehring MA, Spencer MP. Power M-mode Doppler (PMD) for observing cerebral blood flow and tracking emboli. Ultrasound Med Biol. 2002;28:49-57.

45. Choi Y, Saqqur M, Stewart E, Stephenson C, Roy J, Boulanger JM, et al. Relative energy index of microembolic signal can predict malignant microemboli. Stroke. 2010;41:700706.

46. Vos JA, van den Berg JC, Ernst SM, Suttorp MJ, Overtoom TT, Mauser HW, et al. Carotid angioplasty and stent placement: comparison of transcranial Doppler US data and clinical outcome with and without filtering cerebral protection devices in 509 patients. Radiology. 2005;234:493-499.

47. Almekhlafi MA, Demchuk AM, Mishra S, Bal S, Menon BK, Wiebe $S$, et al. Malignant emboli on transcranial Doppler during carotid stenting predict postprocedure diffusion-weighted imaging lesions. Stroke. 2013;44:1317-1322.

48. Padayachee TS, Gosling RG, Bishop CC, Burnand K, Browse NL. Monitoring middle cerebral artery blood velocity during carotid endarterectomy. Br J Surg 1986;73:98-100.

49. Wolf O, Heider P, Heinz M, Poppert H, Sander D, Greil $\mathrm{O}$, et al. Microembolic signals detected by transcranial Doppler sonography during carotid endarterectomy and correlation with serial diffusion-weighted imaging. Stroke. 2004;35:e373-e375.

50. Almekhlafi MA, Couillard PL, Pandya A, Shobha N, Morrish WF, Wong JH, et al. Outcomes after carotid angioplasty and stenting in symptomatic octogenarians. Can J Neurol Sci. 2011;38:446-451.

51. Kamtchum-Tatuene J, Wilman A, Saqqur M, Shuaib A, Jickling GC. Carotid plaque with high-risk features in embolic stroke of undetermined source: systematic review and meta-analysis. Stroke. 2020;51:311-314.

52. Saba L, Saam T, Jäger HR, Yuan C, Hatsukami TS, Saloner D, et al. Imaging biomarkers of vulnerable carotid plaques for stroke risk prediction and their potential clinical implications. Lancet Neurol 2019;18:559-572. 
53. Wodarg F, Turner EL, Dobson J, Ringleb PA, Mali WP, Fraedrich G, et al. Influence of stent design and use of protection devices on outcome of carotid artery stenting: a pooled analysis of individual patient data. $J$ Neurointerv Surg. 2018;10:1149-1154

54. Capoccia L, Sirignano P, Mansour W, d'Adamo A, Sbarigia E, Mariani P, et al. Peri-procedural brain lesions prevention in CAS (3PCAS): randomized trial comparing CGuard ${ }^{\mathrm{TM}}$ stent vs. Wallstent ${ }^{\mathrm{TM}}$. Int J Cardiol. 2019;279:148-153.

55. Leonardi M, Dall'olio M, Raffi L, Cenni P, Simonetti L, Marasco R, et al. Carotid stenting without angioplasty and without protection: the advantages of a less invasive procedure. Interv Neuroradiol. 2008;14:153-163.
56. Bussière M, Pelz DM, Lownie SP. Primary stenting for recurrent stenosis following carotid endarterectomy. Can J Neurol Sci. 2009;36:332-335

57. Criado E, Doblas M, Fontcuberta J, Orgaz A, Flores A. Transcervical carotid artery angioplasty and stenting with carotid flow reversal: surgical technique. Ann Vasc Surg. 2004;18:257261.

58. Texakalidis P, Giannopoulos S, Kokkinidis DG, Charisis N, Kakkar A, Jabbour P, et al. Direct transcervical access vs the transfemoral approach for carotid artery stenting: a systematic review and meta-analysis. J Endovasc Ther. 2019;26:219227. 